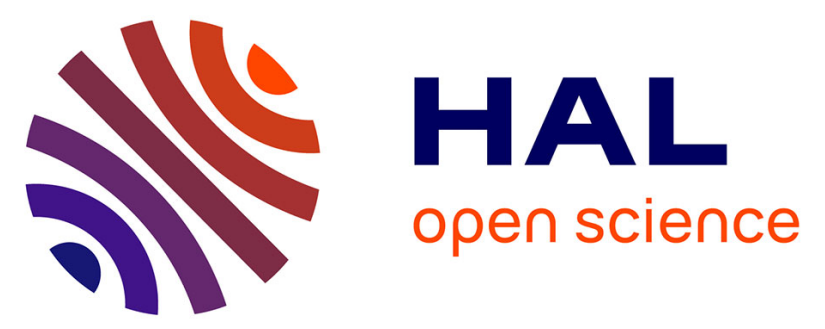

\title{
A Detailed Study of the Metallic Function of Bimetallic Platinum-Rhodium Post Combustion Catalysts by X.A.S., M.E.T.: Correlations with their Catalytic Activity
}

Dominique Bazin, F. Maire, S. Schneider, G. Meunier, F. Garin, G. Maire

\section{To cite this version:}

Dominique Bazin, F. Maire, S. Schneider, G. Meunier, F. Garin, et al.. A Detailed Study of the Metallic Function of Bimetallic Platinum-Rhodium Post Combustion Catalysts by X.A.S., M.E.T.: Correlations with their Catalytic Activity. Journal de Physique IV Proceedings, 1997, 7 (C2), pp.C2841-C2-846. 10.1051/jp4:1997255 . jpa-00255338

\section{HAL Id: jpa-00255338 https://hal.science/jpa-00255338}

Submitted on 1 Jan 1997

HAL is a multi-disciplinary open access archive for the deposit and dissemination of scientific research documents, whether they are published or not. The documents may come from teaching and research institutions in France or abroad, or from public or private research centers.
L'archive ouverte pluridisciplinaire HAL, est destinée au dépôt et à la diffusion de documents scientifiques de niveau recherche, publiés ou non, émanant des établissements d'enseignement et de recherche français ou étrangers, des laboratoires publics ou privés. 


\title{
A Detailed Study of the Metallic Function of Bimetallic Platinum-Rhodium Post Combustion Catalysts by X.A.S., M.E.T.: Correlations with their Catalytic Activity
}

\author{
D. Bazin, F. Maire, S. Schneider, G. Meunier*, F. Garin** and G. Maire** \\ LURE, Bât. 209D, Université Paris-Sud, 91405 Orsay, France \\ * PSA, Centre Technique de Belchamp, 25420 Voujeancourt, France \\ ** LERCSI, URA 1498 du CNRS, 4 rue Blaise Pascal, 67070 Strasbourg, France
}

\begin{abstract}
In automobile catalytic converters, the reaction between carbon oxide $(\mathrm{CO})$ and nitrogen oxides $(\mathrm{NO})$ over $\mathrm{Pt}$ containing catalyst particle is done in order to obtain $\mathrm{CO}_{2}$ and $\mathrm{NO}_{2}$. In this paper, we report a structural characterization of the metallic part of a bimetallic Pt-Rh catalyst conducted through the combined use of three characterization techniques i.e. $\mathrm{X}$-ray absorption spectroscopy (Exafs) and high resolution microscopy by transmission (STEM). Based on all these results, a coherent model seems to distinguish two families of metallic cluster. One is made of nanometric size Pt clusters for which the diameter is less than the nanometer. The second one, made of Pt and $\mathrm{Rh}$ atoms has a diameter more important. For this second one, the repartition of the metals is not statistic. It seems that platinum is at the core of the cluster, the surface being composed by a mixture of $\mathrm{Pt}$ and $\mathrm{Rh}$ atoms.
\end{abstract}

\section{INTRODUCTION}

In automotive catalytic converters, the required reactions [1] are to obtain $\mathrm{CO}_{2}$ and $\mathrm{N}_{2}$ from $\mathrm{CO}$ and $\mathrm{NO}_{\mathrm{x}}$. Among the different catalytic materials, bimetallic platinum-rhodium systems have been extensively studied in large part because of the excellent activity of $\mathrm{Rh}$ for the reduction of nitrogen oxides to nitrogen. In a previous paper, a XAS study of an alumina supported $1 \%$ wtPt- $0.2 \%$ wtRh three way catalyst was conducted $[2,3]$. The results clearly show that the $\mathrm{Rh}$ atoms maintain an oxygen rich environment on exposure to a reducing gas mixture $\left(\mathrm{CO}, \mathrm{NO}, \mathrm{C}_{3} \mathrm{H}_{8}, \mathrm{O}_{2}\right)$. Conversely, the $\mathrm{Pt}$ atoms are reduced. In an other study conducted on academic catalysts for which the metal loading is higher, we have found evidence of true alloy phases at $T>800^{\circ} \mathrm{C}$ [4]. In this paper, we report a detailed structural characterisation of the metallic part of a bimetallic Pt-Rh industrial catalyst conducted through the combined use of two characterisation techniques i.e. X-ray Absorption Spectroscopy (XAS) and high resolution transmission microscopy coupled with X-ray fluorescence analysis. Moreover, a correlation with the catalytic activity is done.

\section{EXPERIMENTAL SECTION}

\subsection{The samples}

Two industrial catalysts containing $0.7 \%$ weight of $P t$ and $0.13 \%$ weight of Rh deposited on cordierite have been studied (see table 1 for the precise content). These two powders, named $\mathrm{RCl}$ and $\mathrm{RC2}$ have been extracted from the converter after respectively $103000 \mathrm{~km}$ and $65000 \mathrm{~km}$.

Table I: Compositions and specific surface areas of the two catalysts.

\begin{tabular}{|c|c|c|c|c|c|c|c|c|}
\hline Catalyst & $\mathrm{S} \mathrm{m}^{2} / \mathrm{g}$ & $\mathrm{Pt}$ & $\mathrm{Rh}$ & $\mathrm{Ce}$ & $\mathrm{P}$ & $\mathrm{S}$ & $\mathrm{Pb}$ & $\mathrm{Zn}$ \\
\hline $\mathrm{RC} \mathrm{1}$ & 9 & 0.72 & 0.13 & 7.6 & 0.82 & 0.14 & 0.29 & 0.32 \\
\hline $\mathrm{RC} 2$ & 13 & 0.68 & 0.13 & 12.7 & 1.19 & 0.17 & 0.17 & 0.37 \\
\hline
\end{tabular}

\subsection{X-ray spectroscopy}

The X-ray absorption spectra were recorded on the Exafs IV station of the LURE laboratory using a Si [111] monochromator for the $\mathrm{L}_{\mathrm{III}}$ edge of $\mathrm{Pt}$, the ring running typically at $1.85 \mathrm{GeV}, 300 \mathrm{~mA}$. All the spectra were recorded in transmission mode and data were analysed using a well-known data processing procedure [5]. The structural parameters (coordination numbers and interatomic distance) of reference compounds used in this

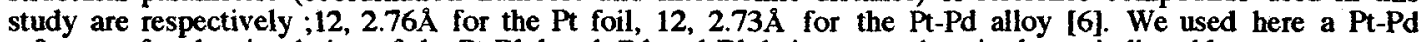
reference for the simulation of the Pt-Rh bond, Pd and $\mathrm{Rh}$ being very close in the periodic table. 


\subsection{Electron microscopy}

Direct imaging of the compounds was carried out with a JEOL 2010 electron microscope coupled to a TRACOR Z-MAX spectrometer. This device allows precise characterisation of the composition of metallic clusters by quantitative $X$-ray fluorescence spectroscopy (E.D.X.). The sample were prepared by crushing the powder in ethanol and then depositing it on a grid.

\subsection{Catalytic activity}

All the measurements were made on a micropilot developed at the LERCSI laboratory [7]. This device was used in a stationary regime with a stochiometry equal to one. Table II gives the characteristics of the device used for the different reaction tests : oxidation of the $\mathrm{CO}$ to $\mathrm{CO}_{2}$, oxidation of $\mathrm{C}_{3} \mathrm{H}_{8}$ to $\mathrm{CO}_{2}$ and the reduction of $\mathrm{NO}_{x}$ to $\mathrm{N}_{2}$. A pretreatment has been done previously under hydrogen at $300^{\circ} \mathrm{C}$ with a flux of $50 \mathrm{~cm}^{3} / \mathrm{min}$ and a heating rate of $4^{\circ} \mathrm{C} / \mathrm{min}$. The mass of the catalyst was $200 \mathrm{mg}$.

Table II : Characteristics of the device used for the measurements of the catalytic activity.

\begin{tabular}{|c|c|c|}
\hline gas & kind of analysis & Specifications \\
\hline $\mathrm{CO}, \mathrm{CO}_{2}$, hydrocarbon & T. R. detector & Binos 1 (Leybold Heraeus) \\
\hline $\mathrm{O}_{2}$ & Paramagnetic analysis & Oxymat 5E(Siemens) \\
\hline NO & Chemiluminescence & 951 (Beckman) \\
\hline
\end{tabular}

\section{RESULTS}

\subsection{Electron microscopy coupled with EDX}

This technique allows us to obtain information on the size distribution of the metallic particles (table III). $D_{X}(\AA)$ is associated to $X \%$ of clusters baving a diameter less than $D_{X}(\AA)$. One of the key result of this technique is the presence of nanometer scale metallic particles even after such severe chemical treatments (high temperature, reduction and oxidation atmospheres).

Table III : Size distributions of the metallic clusters inside the catalysts.

\begin{tabular}{|c|c|c|c|}
\hline Catalyst & $\overline{\mathrm{D}_{25}(\AA)}$ & $\bar{D} 50(\AA)$ & $\mathrm{D}_{75}(\AA)$ \\
\hline$\overline{R C 1}$ & 50 & 80 & 120 \\
\hline$\overline{\mathrm{RC} 2}$ & 30 & 70 & 110 \\
\hline
\end{tabular}

The experimental set up allows also determination of the composition of the metallic particles. It seems that both $\mathrm{Pt}$ and $\mathrm{Rh}$ atoms are present in these particles. The quantitative analysis of the fluorescence data shows that the $\mathrm{Pt} / \mathrm{Rh}$ atomic ratio increases with the size of the particle. More precisely, if we consider metallic particles which have a diameter ranging from $30 \AA$ to $120 \AA$, the atomic ratio increases from 0.5 to 2.92 .

\subsection{Catalytic activity}

A decrease of the activity for the reaction of $\mathrm{NO}_{\mathrm{x}} \rightarrow \rightarrow \mathrm{N}_{2}$ has been attributed to the existence of a Pt$\mathrm{Rh}$ alloy whereas the activities for the reactions of $\mathrm{CO}-->\mathrm{CO}_{2}$ and $\mathrm{C}_{3} \mathrm{H}_{8}-->\mathrm{CO}_{2}$ were linked to the existence of monometallic Pt clusters [8].

\subsection{X-ray absorption spectroscopy}

It is well known that the intensity of the so-called white line can be related to the occupation of the 5d band in the case of Pt atom [9]. The white line associated with the catalysts is plotted on figure 1 and indicates a metallic state for the Pt atom. Thus the coordination sphere of the Pt atoms is principally composed of Pt and/or $\mathrm{Rh}$ atoms. This qualitative analysis is supported by the numerical simulation of the Exafs modulations. Figure 2 shows the quality of agreement obtained for one of the catalysts and as reported in table IV we can see that the first coordination sphere of the Pt is mostly Pt. As pointed out before, it is possible to differentiate the contributions coming from Pt or Rh atoms. In table IV, NPtPt is related to the number of Pt atoms around a Pt atom and NPtRh the number of $\mathrm{Rh}$ atoms around a Pt atom.

Table IV : Quantitative analysis at the $\mathrm{Pt} \mathrm{L}_{\mathrm{II}}$ edge.

\begin{tabular}{|c|c|c|}
\hline Catalyst & Neighbourhood & Distance $(A)$ \\
\hline RC1 & NPtPt $=7.0$, NPtRh $=2.0$ & $R_{P t P t}=2.76, R_{P t R h}=2.76$ \\
\hline RC2 & NPtPt $=6.0$, NPtRh $=2.0$ & RPtPt $=2.75$, RPtRh $=2.76$ \\
\hline
\end{tabular}




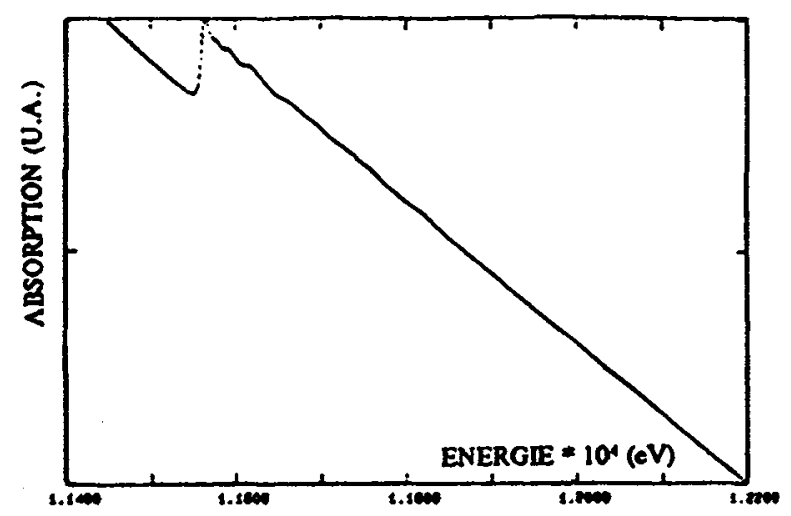

Difure 1 : Pt Lm odge as measured for the industrial catalyst RC2.

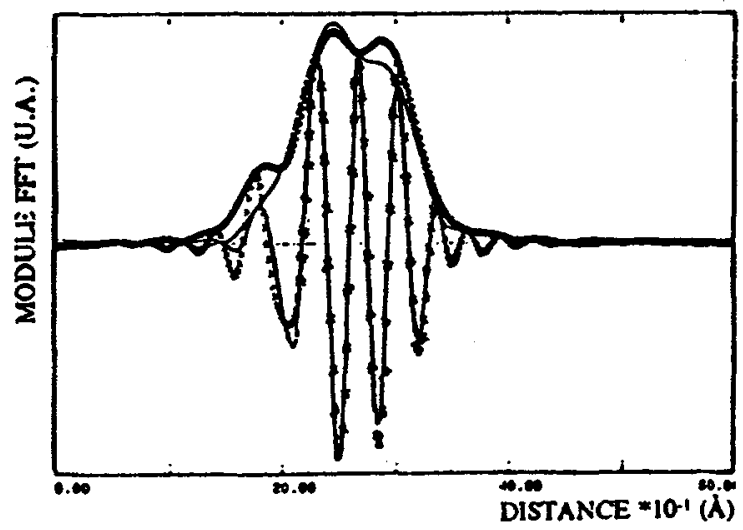

Floure 2: Numerical simulation of the Exafs modulations for the catalyst RC2.

\section{MODELISATION}

If we want now to describe from a structural point of view the metallic function of the catalyst, we have to take account of all the results given by the different techniques we have used (M.E.T.-E.D.X., catalytic activity, X.A.S.). The starting point of this modelisation is obviously given by the electron microscopy (table III) which reveals the presence of metallic particle of different sizes (from $20 \AA$ to $120 \AA$ ) and different compositions (the atomic ratio ranging from 0.5 to 2.92 ). If we contate this result to those given by the concentrations of the samples (table I) we can see that there is a major contradiction, the atomic $\mathrm{Pt} / \mathrm{Rh}$ ratio being equal for these two samples to approximately $2.9(0,72 \%$ weight of $\mathrm{Pt} 0,13 \%$ weight of $\mathrm{Rh}$ for $\mathrm{RCl}$ and $0,68 \%$ weight of $\mathrm{Pt} \cdot 10,13 \%$ weight of $\mathrm{Rh}$ for $\mathrm{RC2}$ ). To overcome this difficulty, we have to suppose the presence of nanometer scale particles which are composed principally of $P t$ and which cannot be seen by electron microscopy, the detection power of the device being larger than the diameter of this kind of particle. This first analysis on the composition of the material which thus supposes two phases, one of monometallic Pt clusters and another made of bimetallic clusters which have a greater diameter is in line with the catalytic activity of the samples. As pointed out previously, we have seen that only the existence of two kinds of metallic cluster can explain the different activities. The presence of such small Pt particles explains also why the Pt coordination of the Pt is so small. We have already shown that for clusters which have a diameter greater than $30 \AA$, the total coordination (NPtPt $+N P t R h$ ) has to be close to 11 [10] and not 9 as indicated in table IV. Thus, at this step of the analysis, all the techniques we have used i.e. T.E.M.-E.D.X, Exafs and catalytical activity seem to show that the material is made of two kinds of metallic clusters. The first family is associated with nanometer scale $\mathrm{Pt}$ clusters, the second one is made of $\mathrm{Pt}-\mathrm{Rh}$ bimetallic clusters for which the diameter is between $30 \AA$ and $120 \AA$. The question now is the following : What is the distribution of the two metals inside the bimetallic cluster? Is it a statistical distribution or do we have one metal at the surface and the other one at the core? This question is very important because the composition of the surface is clearly linked to the catalytic activity [11]. Because this information is not so easy to get [12], a detailled step by step analysis is needed. All the clusters we considered up to now have a cubooctahedral morphology. We choose this kind of cluster because this is the more stable, the surface tension being the smaller [13]. We can now explore several 
possibilities for the distribution of the two kinds of metals, $\mathrm{Pt}$ and $\mathrm{Rh}$, inside the clusters. In the case of a statistical distribution of the two metals, the different coordination numbers (NPtPt, NPtRh) calculated for the clusters A, B, C with different diameters are resumed in table $\mathrm{V}$.

Table V : Statistical distribution of the two metals inside the clusters.

\begin{tabular}{|c|c|c|}
\hline Statistical distribution & NPtPt & NPtRh \\
\hline $\begin{array}{c}\text { Cluster } A: \text { Diameter of } 30 \AA: 2869 \text { atoms } \\
\text { atomic ratio Pt/Rh equal to 1.0close to the value given by EDX equal to } 1.0\end{array}$ & 5.43 & 5.43 \\
\hline $\begin{array}{c}\text { Cluster B : Diameter of } 50 \AA: 14993 \text { atoms } \\
\text { atomic ratio Pt/Rh equal to } 1.45 \text { close to the value given by EDX equal to } 1.45\end{array}$ & 6.8 & 4.5 \\
\hline $\begin{array}{c}\text { Cluster C:Diameter of } 80 \AA: 69355 \text { atoms } \\
\text { atomic ratio Pt/Rh close to the value given by EDX }(1.6)=1.6\end{array}$ & 7.13 & 4.46 \\
\hline
\end{tabular}

If an average is done now between the different coordination numbers obtained for this family of cluster (A, B and C : statistical distribution) and the coordination number associated with nanometer scale monometallic Pt clusters (NPtPt $=5$., NPtRh $=0$.), it is definitely not possible to get the experimental results $(\mathrm{NPtPt}=7 ., \mathrm{NPtRh}=2$.) resumed in table IV. In fact, it is obvious that the number of the Pt-Pt bonds is too low. In order to reach the observed value, we must increase this structural parameter i.e... considering a core of the cluster which is just composed of Pt atoms. Thus, we build another family of clusters composed of a core of Pt atoms on the surface of which we put several shells of pure Rh atoms in order to respect the atomic ratio. In table VI, we have compiled the coordination numbers calculated for this family denoted as clusters D, E and $\mathrm{F}$.

Table VI: Clusters of pure Pt atoms covered by several shells of pure Rh atoms.

\begin{tabular}{|c|c|c|c|}
\hline & Distribution & NPtPt & NPtRh \\
\hline $\begin{array}{l}\text { Cluster } \mathrm{D} \text { : diameter } 30 \AA: 2869 \text { atoms } \\
\text { atomic ratio } \mathrm{Pt} / \mathrm{Rh} \text { equal to } 0.9 \text { close to the value given by } \mathrm{EDX} \text { equal to } 1.0\end{array}$ & $\begin{array}{l}\text { Core : } 1415 \mathrm{Pt} \\
\text { Surface : } 1454 \mathrm{Rh}\end{array}$ & 10.56 & 1.43 \\
\hline $\begin{array}{l}\text { Cluster } E \text { : diameter } 50 \AA: 17199 \text { atoms } \\
\text { atomic ratio } P t / R \text { h equal to } 1.4 \text { close to the value given by EDX equal to } 1.4\end{array}$ & $\begin{array}{l}\text { Core : } 10179 \mathrm{Pt} \\
\text { Surface : } 7020 \mathrm{Rh}\end{array}$ & 11.25 & 0.75 \\
\hline $\begin{array}{l}\text { Cluster } F: \text { diameter } 80 \AA: 69355 \text { atoms } \\
\text { atomic ratio } P t / R h \text { equal to } 1.6 \text { close to the value given by } E D X \text { equal to } 1.6\end{array}$ & $\begin{array}{l}\text { Core : } 43287 \mathrm{Pt} \\
\text { Surface : } 26068 \mathrm{Rh}\end{array}$ & 11.56 & 0.44 \\
\hline
\end{tabular}

For this new family (clusters D, E, and F), the number of Pt-Pt bonds seems to be correct. At the contrary, the number of Pt-Rh (NPtRh) is too weak. This kind of distribution of the two metals inside the clusters has thus to be rejected. If we build several clusters which are constituted by a core of $R h$ atoms on which several shells of Pt atoms have been deposited (as in table VII: clusters G, H, and I), this situation is also not favorable and this kind of configuration has to be rejected also.

Table VII : Rh atoms on which several shells of Pt atoms have been deposited

\begin{tabular}{|c|c|c|c|}
\hline & Distribution & NPtPt & NPtRh \\
\hline Cluster G $:$ diameter $30 \AA: 2869$ atoms & Core $: 1415 \mathrm{Rh}$ & 8.36 & 1.39 \\
atomic ratio Pt/Rh equal to 0.9 close to the value given by EDX equal to 1.0 & Surface $: 1454 \mathrm{Pt}$ & \\
\hline $\begin{array}{c}\text { Custer } \mathrm{H}: \text { diameter } 50 \AA: 17199 \text { atoms } \\
\text { atomic ratio PU/Rh equal to } 1.3 \text { close to the value given by EDX equal to } 1.4\end{array}$ & $\begin{array}{c}\text { Core }: 10179 \mathrm{Rh} \\
\text { Surface }: 7020 \mathrm{Pt}\end{array}$ & 9.43 & 0.95 \\
\hline $\begin{array}{c}\text { Cluster } I: \text { diameter }: 80 \AA: 69355 \text { atoms } \\
\text { atomic ratio PURh equal to } 1.6 \text { close to the value given by EDX equal to } 1.6\end{array}$ & $\begin{array}{c}\text { Core }: 43287 \mathrm{Rh} \\
\text { Surface }: 26068 \mathrm{Pt}\end{array}$ & 10.17 & 0.76 \\
\hline
\end{tabular}

In fact, it seems that the two repartitions we have considered above : the statistical distribution (clusters $A, B$, and $C$ : table $V$ ) and complete demixion of the metals inside the clusters (D, E and F : table VI and clusters $\mathrm{G}, \mathrm{H}, \mathrm{I}$ table VII) have to be dismissed. A last configuration is now considered in which a core of Pt atoms is covered by several shells of a Pt-Rh alloy. An example is given in table VIII for which the core of the cluster is made of 3871 atoms of $\mathrm{Pt}$, the surface being composed by an alloy of $\mathrm{Pt}_{50} \mathrm{Rh}_{50}$ as already observed and reported previously for model catalysts [2].

Table VIII : Core of Pt atoms on which several shells of an alloy of Pt50Rh50 have been deposited.

\begin{tabular}{||c|c|c|c|}
\hline & Distribution of the two metals & NPtPt & NPtRh \\
\hline \multicolumn{3}{|c|}{ The core of the cluster is composed of 3871 atoms of Pt } & \\
\hline Cluster J : diameter $: 50 \AA: 17199$ atoms & $\begin{array}{l}\text { Sufface }: \text { alloy made of } 6664 \\
\text { atomic ratio Pt/Rh equal to } 1.58 \text { close to the value given by } \\
\text { EDX eqaul to } 1.4\end{array}$ & $\mathbf{P t}$ atoms and 6664 Rh atoms & 2.81 \\
\hline
\end{tabular}


As we can see in table VIII, it is clear that now the two different coordination numbers as calculated for this cluster are lined with the experimental results given by T.E.M.-E.D.X.; X.A.S. and catalytic tests.

\section{DISCUSSION}

Let's begin the discussion by considering the surface segregation in a bulk alloy compound. Since many properties of technological interest are related to surface segregation, this research field has given rise to a large amount of work in the past decade in surface science [14-16]. In the case of Pt-Rh alloys surface, numerous works have been conducted. Firstly, as pointed out by VAN DELFT et al. [17], the surface segregation is extremely sensitive to trace of impurities. Among the experimental studies, whereas ion scattering spectroscopy [18] or Auger electron spectroscopy [17], a strong Pt surface enrichment has been tevealed. More precisely, BECK et al. [19] have shown that under reducing conditions, the surface composition is enriched in Pt while under oxidising conditions, the surface layer quickly becomes enriched in $\mathrm{Rh}$. From a theoretical point of view, LEGRAND and TREGLIA [20] have shown that a Tight Binding Ising model calculation of surface segregation in Pt-Rh alloys leads to a Pt surface enrichment whatever the bulk concentration and temperature. This approach have pointed out that the leading term in such approach is the local surface field which has been proved to be related to the difference in surface tension between the pure constituents.

Let's move now from surface to cluster. From an experimental point of view, WAND and SCHMIDT [21] have studied PtRh particles deposited on silica and have founded that upon heating to $500^{\circ} \mathrm{C}$, particles coalescence into roughly their original morphologies but the cores are primarily Pt and surfaces of particles are enriched in $\mathrm{Rh}$. The same authors have also pointed out that a $\mathrm{Rh}$ surface enrichment of the PtRh alloy particle by oxidation-reduction cycling [22]. We have also to report the work of H. ROBOTA et al.[23]. In their paper, model automotive exhaust catalysts have been examined by EXAFS, STEM and XRD in order to determine the state of $\mathrm{Pt}$ and $\mathrm{Rh}$ following stimulated exhaust treatments. Through the combined use of all three characterisation techniques, the resulting Pt-Rh alloy particles are found to be solid solutions with no evidence for preferential $\mathrm{Rh}$ enrichment of the particle surfaces. Nevertheless, if one proceed to a careful examination of this work, some points can explain this discrepancy. At first, the system is based on model catalyst, it is definitely not our case. They use calculated tables of Teo and Lee for the fitting procedure and not experimental reference compounds. Finally, the different catalyst which have been studied undergo in lab chemical treatment and we have already showed that this kind of protocol cannot simulate the post combustion process. Theoretical studies have also been made on surface segregation in Pt-Pd alloy particles, a system very close to the Pt-Rh one. In this particular case, the main result of this study is that Pd atoms strongly segregate at the surface whatever the concentration and the temperature [24].

\section{CONCLUSION}

This modelisation based on the results coming from three different techniques conclude to the presence inside the materials of two kinds of metallic clusters :

- a family of nanometer scale monometallic Pt clusters,

- another family of Pt-Rh bimetallic clusters for which the core is constituted principally of $\mathrm{Pt}$ atoms and the surface is made of a Pt-Rh alloy.

Nevertheless, we have to be very cautious to the precise composition of the surface of the bimetallic clusters due to the complexity of such catalytic materials (aged commercial catalysts). The limit of such a modelisation based only on XAS results has been already underlined in previous work [12]. The fact that this model was built through the combined use of three characterisation techniques reinforces our hypotheses of metallic multiphases on the surface of the catalysts.

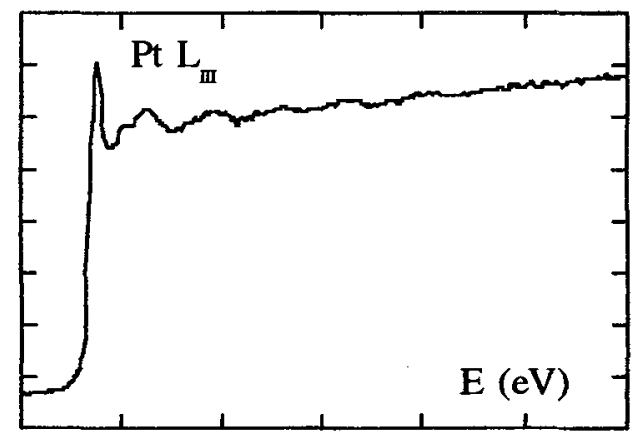

11500116001170011800119001200012100

Figure 3 : Absorption spectrum (fluorescence mode) of an industrial three way catalyst. 
The next step in fact is to do in situ Exafs studies of the converters. If a solid detector is used in order to get an absorption spectrum in the fluorescence mode, this kind of approach can be made. As an example we show on figure 3 the data which can be collected with such device. Works are in progress to simulate the industrial conditions.

[1] H. HENSSLER : Proc, CAPOC II, Studies in Surf. Sci. and Cat. Ed. A. CRUCQ, Elsevier (1991) 35.

[2] F. MAIRE, M. CAPELLE, G. MEUNIER, J. F. BEZIAU, D. BAZIN, F. GARIN, J. L. SCHMITT, G. MAIRE, Preprints CAPOC III, 1(1994), 161.

[3] V. PITCHON, C. HOWITT, F. MAIRE, D. BAZIN, P. BERNHARDT, G. MAIRE, NIM B 97(1995) 33.

[4] F. MAIRE, D. BAZIN, G. MEUNIER, F. GARIN, G. MAIRE, accepted in J. de Physique.

[5] D. BAZIN, H. DEXPERT, P. LAGARDE, Topics in Cur. Chem. 145, 69 (1988), Ed. Springer-Verlag. HARADA M., ASAKURA K., TOSHIMA N. , J. of Phys. Chem. 98(10) 1994 2653-62 M. WEIBEL, Thesis, Université Louis Pasteur, Strasbourg (1991).

[8] F.MAIRE, Thesis , Universite Louis Pasteur, Strasbourg (1994).

[9] A. N. MANSOUR, J. W. COOK, D. E. SAYERS, J. Phys. Chem. 88, 2330 (1984).

[10] D. BAZIN, D. SAYERS, Jpn J. Appl. P., Vol. 32 (1993) Suppl. 32-2 p 249

[11] G. H. VIA, K. F. DRAKE, G. MEITZNER, F.W. LYTLE, J.H. SINFELT Cat. let. 5(1990)25.

[12] J. MOONEN, J. SLO, L. LEFFERTS, D. BAZIN, H. DEXPERT, Physica B 208 (1995) 689.

[13] S. INO, J. Phys. Soc. Jap. 27(1969)941.

[14] M. J. KELLEY and V. PONEC, Prog. Surf. Sci. 11(1981)139.

[15] M.J. SPARNAAY, Surf. Sci. Rep. 4(1985) 101

[16] P. M. OSSIS, Surf. Sci. 201(1988)L519.

[17] F. C. M. van DELFT, B.E. NIEUWENHUYS, Surf. Sci. $178(1986) 880$.

[18] F. L. WILLIAMS, G. C. NELSON Appl. Surf. 3(1979) 409.

[19] D. D. BECK, C. L. DIMAGGIO, G. B. FICHER Surf. Sci. 297(3)(1993) 303

[20] B. LEGRAND, G. TREGLIA, Surf. Sci. $236(1990) 398$.

[21] T. WANG, L. D. SCHMIDT, J. of Cat. 70(1981)187.

[22] Y.ZHU, L. D. SCHMIDT Surf. Sci. 129(1983)107.

[23] H. J. ROBOTA, R. W. BROACH, J. W. A. SACHTLER, S. A. BRADLEY, Ultramicros. 22 (1987)149

[24] A. KHOUTAMI, thesis, Université Paris XI, 1993. 